\title{
Initial REM Sleep Suppression by Clomipramine: A Prognostic Tool for Treatment Response in Patients with a Major Depressive Disorder
}

\author{
Dominique Höchli, Dieter Riemann, Jürgen Zulley, and \\ Mathias Berger
}

\section{Introduction}

Kupfer et al. $(1976,1981)$ demonstrated, in a sample of 82 depressed patients, that the amount of rapid eye movement (REM) sleep suppression during the initial 2 nights of treatment with amitriptyline correlated positively with clinical response. Gillin et al. (1978) were able to replicate this finding in six depressed patients. From these results, it may be speculated that polysomnographic measurement of REM sleep in patients during the initial nights of treatment with antidepressive drugs may offer the possibility of improving drug therapy. Whereas in clinical practice the response to antidepressive medication can only be evaluated after at least 10-14 days of medication (Woggon 1983), the predictive value of REM sleep changes may allow us to avoid unsuccessful treatment early in the course of therapy. The above-cited studies raise the question of whether or not it is possible to establish the threshold of initial REM sleep suppression necessary for successful drug therapy, thereby providing a substantial differential-therapeutic tool that could influence the choice of drug or dosage. The aim of the present

From the Max-Planck-Institute of Psychiatry, München 40, F.R.G. Address reprint requests to Dr. M. Berger, Psychiatric Department II, Max-Planck-Institute of Psychiatry, Kraepelinstr. 10, D-8000 München 40 , F.R.G.

Received March 8, 1986; revised April 19, 1986. study was to test this hypothesis with clomipramine, which is characterized as producing the most profound suppression of REM sleep (Chen 1979).

\section{Methods}

Ten inpatients ( 7 women, 3 men) with a major depressive disorder, endogenous subtype, according to Research Diagnostic Criteria (RDC) (Spitzer et al. 1977) (3 bipolar and 7 unipolar), who ranged in age from 18 to 59 years (mean $40.2 \pm 15.4$ years) and had a 21 -item Hamilton score ranging from 21 to 36 points (mean $28.2 \pm 5.2$ ) were included in the study. Psychotic patients and patients with a severe suicidal risk were excluded. All patients were drug free for at least 3 weeks. Sleep was recorded polysomnographically on one baseline night, preceded by two adaptation nights. Further sleep recordings were made during the nights 1 and 19 of medication. Sleep recordings were scored visually according to standardized criteria (Rechtschaffen and Kales 1968). Additionally, recordings were videotaped for later automated analysis, which has not yet been undertaken. On the first day of medication, at 4:00 PM, patients received $75 \mathrm{mg}$ of clomipramine. From the second day on, patients were given a daily total of $150 \mathrm{mg}$ of clomipramine in 3 portions at 8:00 AM, 12:00 noon, and 4:00 PM. To estimate the effects of therapy, patients were rated 
by means of the 21-item Hamilton scale during baseline and on the 19th day of drug treatment. Additionally, patients self-rated their mood before and after each night in the laboratory along the Adjective Mood Scale (AMS) (von Zerssen 1986).

\section{Results}

The effects of clomipramine on sleep variables in comparison to baseline are shown in Table 1. With regard to variables of sleep continuity, treatment with clomipramine led to a significant increase of sleep latency and a decrease of sleep efficiency after 19 days of treatment. Parameters of sleep architecture were also affected: Stage I [percent sleep period time (\%SPT)] was significantly enhanced after 19 treatment days, whereas Stage 2 was increased only on the first treatment day and later returned to baseline levels. In summary, clomipramine treatment does not seem to improve sleep quality but actually seems to impair sleep. Regarding REM sleep measures, REM latency was significantly lengthened during the initial drug night, and
REM sleep (\%SPT) was markedly reduced compared to baseline. Four patients even showed a complete absence of REM sleep during the first drug night. On day 19 of clomipramine treatment, mean REM latency was still 3 times longer than during the baseline night; although REM sleep suppression was still highly significant, there was a slight attenuation of REM sleep suppression during the treatment period. Only two patients showed total REM suppression during the 19th night.

As demonstrated in Table 2, patients significantly improved after 19 days of treatment as measured by the 21 -item Hamilton scale and the mean of morning and evening values (AMS). As a measure of clinical response, the Hamilton value on the 19th day was calculated as percentage of the corresponding value during baseline for each patient. Establishing a response criterion of at least $30 \%$ improvement or more on the 21-item Hamilton scale, 6 of the 10 patients responded well to clomipramine treatment. By relating the change in REM sleep (\%SPT) from baseline night to the first night of treatment to this measure of clinical response.

Table 1. Sleep Parameters in 10 Depressed Patients during Baseline and Treatment with Clomipramine (Mean $\pm S D)$

\begin{tabular}{|c|c|c|c|}
\hline & \multirow{2}{*}{$\begin{array}{c}\text { Baseline } \\
\text { night }\end{array}$} & \multicolumn{2}{|c|}{ Clomipramine treatment } \\
\hline & & Night 1 & Night 19 \\
\hline \multicolumn{4}{|l|}{ Sleep continuity variables } \\
\hline Sleep latency (min) & $17.6 \pm 16.1$ & $29.6 \pm 30.5$ & $34.1 \pm 23.4$ \\
\hline Early moming awakening (min) & $10.9 \pm 20.8$ & $30.9 \pm 50.4$ & $39.8 \pm 49.1$ \\
\hline Time awake (\% SPT $\left.{ }^{a}\right)$ & $9.2 \pm 12.0$ & $6.3 \pm 6.0$ & $13.3 \pm 8.2$ \\
\hline Sleep efficiency (\%) & $85.4 \pm 15.5$ & $81.7 \pm 12.5$ & $72.3 \pm 13.5^{i}$ \\
\hline \multicolumn{4}{|l|}{ Sleep architecture } \\
\hline Stage $1(\%$ SPT $)$ & $8.1 \pm 4.1$ & $9.1 \pm 6.7$ & $19.5 \pm 8.0$ \\
\hline Stage $2(\%$ SPT $)$ & $50.3 \pm 10.8$ & $60.2 \pm 13.4^{*}$ & $49.6 \pm 13.0$ \\
\hline Slow-wave sleep (\%SPT) & $12.2 \pm 8.0$ & $20.0 \pm 12.3$ & $10.7 \pm 8.3$ \\
\hline \multicolumn{4}{|l|}{ REM sleep variables } \\
\hline REM latency (min) & $64.7+29.7$ & $\begin{array}{c}197.5 \pm 68.5^{3} \\
\text { (n) }=6)\end{array}$ & $\begin{array}{c}220.7=55.5 \\
(n=8)\end{array}$ \\
\hline REM (\%SPT) & $19.7 \pm 3.6$ & $2.9 \pm 3.0$ & $5.4 \pm 5.7$ \\
\hline
\end{tabular}

"SPT, sleep period time-time from sleep onset till final awakening.

${ }^{b_{p}}<0.05$ in comparison $t \omega$ baseline (Wilcoxon test two-lailed).

$p<0.01$ in comparison to baseline. 
Table 2. Psychopathometric Measurements during Baseline and after 19 Days of Clomipramine Treatment in 10 Patients (Mean \pm SD)

\begin{tabular}{lcc}
\hline & Baseline & $\begin{array}{c}\text { Day 19 } \\
\text { of treatment }\end{array}$ \\
\hline 21-Item Hamilton Score & $28.2 \pm 5.2$ & $16.3 \pm 9.5^{b}$ \\
$\begin{array}{l}\text { AMS (mean of morning } \\
\text { and evening values) }\end{array}$ & $39.9 \pm 9.4$ & $30.3 \pm 13.4^{a}$ \\
\hline
\end{tabular}

${ }^{a} p<0.05$ in comparison to baseline (Wilcoxon test, one-tailed). ${ }^{b} p<0.01$ in comparison to baseline.

a significant correlation emerged $(r=-0.64$, $p<0.05$; Spearman Rank correlation, one-tailed) (Figure 1). This means that the higher the REM sleep reduction during the first night of treatment in comparison to baseline, the better the clinical improvement. Concerning patients' self-rating of mood, however, the same correlation did not show statistical significance $(r=-0.44$; Spearman Rank correlation, one-tailed). In con- trast to Kupfer et al. (1976, 1981) and Gillin et al. (1978), changes in REM latency from baseline to the first drug night did not correlate with clinical improvement. This may be due to the fact that REM latency was determinable only for six patients during the first drug night, as clomipramine treatment led to total REM sleep suppression in four subjects. For the same reason, neither changes in REM density nor first REM-episode duration from baseline to first treatment night yielded significant correlations with therapy response. Considering changes in all the other sleep variables (see Table 1) from baseline to first treatment night, no significant correlations with therapy response could be found.

\section{Discussion}

By studying the effects of clomipramine in 10 depressed patients and monitoring REM sleep variables during baseline, initial night of treat-

Figure 1. Relationship between REM sleep suppression and clinical response in 10 depressed patients (line represents regression line).

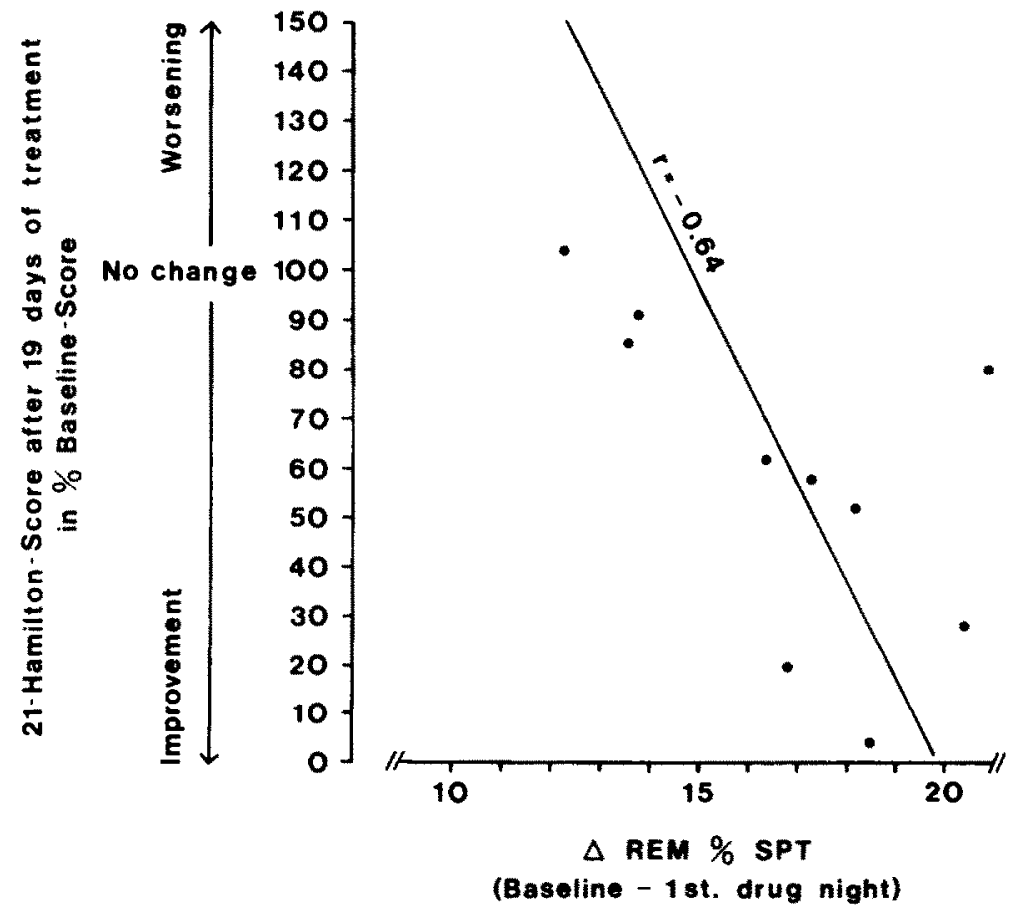


ment, and after 19 days of treatment, the potent REM suppressing efficiency of this drug could be demonstrated. Even a dose of $75 \mathrm{mg}$ of clomipramine led to total REM suppression in 4 of the 10 patients during the first night of drug administration. This is in good agreement with Chen (1979), who claimed that clomipramine is the most potent REM-suppressing tricyclic agent. The most interesting result of the present study is further illustrated by Figure 1 .

As already mentioned. the amount of REM sleep suppressed on the initial night of drug treatment in comparison to baseline seems to be a good predictor of clinical response. Figure 1 illustrates the relationship between reduction in REM sleep and clinical response. For example, choosing a cut-off score for REM sleep suppression of $15 \%$ SPT, only one of the seven patients showing higher REM sleep reduction did not react in the expected way, i.e., did not respond to clomipramine treatment although suppressing more than $15 \%$ REM sleep. On the other hand, the remaining three patients showing a reduction of REM sleep of less than 15\% SPI are the clinically less responsive patients. To further validate this finding, and to perhaps establish the general cut-off score of REM sleep suppression necessary to promote positive clinical response, studies involving larger samples of depressed patients and using other antidepressant drags should certainly be conducted. In any case, the monitoring of REM sleep during antidepressant treatment seems to be a promising predictor of the efficacy of drug therapy in depressive disorders. In contrast to Kupfer et al.
(1981), who administered amitriptyline, the initial shortening of sleep latency did not predict therapy response. This discrepancy might be due to different properties of the drugs studied in regard to sleep continuity.

\section{References}

Chen C (1979): Sleep, depression and antidepressants. Br J Psychiatry 135:385-402.

Gillin JC, Wyatt RJ, Fram D, Snyder F (1978): The relationship between changes in REM sleep and clinical improvement in depressed patients treated with amitriptyline. Psychopharmacology 59:267-272.

Kupfer DJ, Foster FG, Reich L, Thompson KS, Weiss B (1976): EEG sleep changes as predictors in depression. Am I Psychiatry 133:622-626.

Kupfer DJ, Spiker DG, Coble PA, Ncil JF, Ulrich R, Shaw DH (1981): Sleep and treatment prediction in endogenous depression. Am J Psychiatry 138:429-434.

Rechtschaffen A, Kales AA (1968): A Manual of Standardized Terminology, Techniques, and Scoring for Steep Stages of Human Subjects. Washington, DC: Department of Health, Education and Welfare,

Spitzer RL, Endicott JE, Robins E (1977): Research Diagnostic Criteria for a Selected Group of Functional Disorders (3rd ed). New York: New York State Psychiatric Institute, Biometric Research.

Woggon B (1983): Prognose der Psychopharmakotherapie. Stuttgart: Enke.

Zerssen D von (1986): Clinical self-rating scales (CSRS) of the Munich Psychiatric Information System (PSYCHIS München). In Sartorius N, Ban $T$ (eds). Assessment of Depression. Berlin: Springer. pp 270-303 